\title{
Uptake of prenatal genetic diagnosis and termination of pregnancy by Omani Muslim families at risk of genetic disorders: experience over a 9-year period
}

\author{
Zandré Bruwer ${ }^{1}$. Salwa Al Ubaidani ${ }^{3} \cdot$ Khalsa Al Kharusi $^{1}$. Fathiya Al Murshedi ${ }^{1}$ Almundher Al-Maawali ${ }^{1}$. \\ Abeer Al Sayegh ${ }^{1}$. Adila Al Kindy ${ }^{1}$. Nihal Al Riyami ${ }^{2} \cdot$ Tamima Al Dughaishi $^{2} \cdot$ Mouza Al Salmani $^{3}$. \\ Nadia Al Hashmi ${ }^{4}$. Maryam Al Shehhi ${ }^{4}$. Badriya Al Fahdi ${ }^{3}$. Sumaya Al Amri ${ }^{3} \cdot$ Khalid Al-Thihli $^{1}$
}

Received: 26 January 2022 / Accepted: 11 February 2022 / Published online: 18 February 2022

(c) The Author(s), under exclusive licence to Springer-Verlag GmbH Germany, part of Springer Nature 2022

\begin{abstract}
Studies on the acceptance of prenatal diagnosis and termination of pregnancy for single gene disorders within Islamic societies in the Middle East are limited. A few have examined the attitudes toward pregnancy termination for fetal indications, but a dearth of published data exists on actual behavior and uptake. This study reports on all prenatal diagnosis requests for single gene disorders, from the Sultanate of Oman, over 9 years. A retrospective study was conducted during which the medical records of all women who performed prenatal diagnoses for single gene disorders were reviewed. A total of 148 invasive procedures were performed for 114 families. The total number of yearly requests for prenatal diagnosis increased exponentially from three in 2012 to 21 in 2020. Sixty-four different diagnoses were tested for with the majority being autosomal recessive in nature. Seventy-one percent (28/39) of cases where an affected pregnancy was identified were terminated. Fifty-two of the 114 women (45.6\%) repeated prenatal diagnosis in a future pregnancy. Seventy-two couples (63\%) were consanguineous parents related as second cousins or closer. The majority of tests performed were for couples from Muscat (27\%), Albatinah (27\%), and Alsharqiya (20.3\%) governorates in Oman. The findings of this study provide evidence that prenatal diagnosis is an acceptable reproductive option to prevent the occurrence of genetic disorders that meet termination eligibility criteria as outlined by the Islamic Jurisprudence (Fiqh) Council Fatwa, among Omani Muslim couples.
\end{abstract}

Keywords Prenatal genetic diagnosis $\cdot$ Termination of pregnancy $\cdot$ Genetic disorders $\cdot$ Oman $\cdot$ Muslim

\section{Introduction}

Salwa Al Ubaidani and Khalsa Al Kharusi contributed equally.

Zandré Bruwer

zandrebruwer@gmail.com

1 Genetic and Developmental Medicine Clinic, Sultan Qaboos University Hospital \& Department of Genetics, Sultan Qaboos University, Muscat, Sultanate of Oman

2 Department of Obstetrics and Gynaecology, Sultan Qaboos University Hospital, Muscat, Sultanate of Oman

3 Department of Obstetrics and Gynaecology, Fetal Medicine Unit, Royal Hospital, Ministry of Health, Muscat, Sultanate of Oman

4 National Genetic Centre, The Royal Hospital, Ministry of Health, Muscat, Sultanate of Oman
The incidence of genetic diseases and congenital anomalies in the Arab world is known to be significantly higher than in Western countries. In the Sultanate of Oman, located in the south-eastern part of the Arabian Peninsula and bordered by the United Arab Emirates, Saudi Arabia, and Yemen, these figures reach $7 \%$ as compared to the $2-3 \%$ reported globally (Modell 2002; Rajab et al 2013, 2014). The increased prevalence of the genetically determined disorders has been largely attributed to consanguinity and the preference for tribal and clan endogamy, as is customary for most Arab communities (Al-Gazali et al 2006; Al-Thihli et al 2014; Bittles 2001; Bittles and Hamamy 2010; Bruwer et al 2014; Rajab and Patton 2000). The national survey figures for Oman support high consanguinity rates with 52\% of all Omani marriages recorded as consanguineous (AlRiyami et al. 2000). Rajab and Patton (2000) also reported 
an average inbreeding coefficient $(F)$ of 0.0198 from their large, clinic-based study, involving more than 60,000 Omani couples (Rajab and Patton 2000). In addition, the authors identified that $36 \%$ of marriages were between first and second cousins and $20.4 \%$ were classified as marriages between the same tribe. This practice, of consanguineous and endogamous marriage, has partly contributed to the burden of rare recessive genetic disorders in these communities. The additive risk being mainly attributed to shared carrier status for homozygous variants (Al-Gazali et al 2006).

Autosomal recessive disorders are associated with a recurrence risk of $25 \%$ for each future pregnancy. Where molecular confirmation has been reached, prenatal genetic diagnosis (PND) can be offered as an option to couples to determine if the pregnancy is affected or not. PND involves an invasive procedure such as chorionic villous sampling (CVS) (offered during the first trimester) or amniocentesis (offered during the second trimester or any later gestational age), to facilitate diagnostic testing for the genetic disorder. While CVS allows for the result at an earlier stage of pregnancy, which has emotional as well as technical benefits as compared to termination undertaken later on, the sensitivity is slightly lower than that of amniocentesis ( $98 \%$ versus 99.9\%). The accuracy is affected by the consideration of confined placental mosaicism when sampling chorionic villi (Navaratnam and Alfirevic 2021). Both invasive procedures are associated with a risk of pregnancy loss. Based on a large meta-analysis study, the rate of procedure-related pregnancy loss that is attributable to either CVS or amniocentesis is approximately $0.22 \%$ and $0.11 \%$ respectively (Akolekar et al 2015). PND services for single gene disorders are available in two tertiary centers in Oman, Sultan Qaboos University Hospital (SQUH) and Royal Hospital (RH). These hospitals offer clinical genetic services and molecular diagnostic laboratories, although PND molecular tests are usually outsourced to overseas molecular diagnostic laboratories. Healthcare is available to all Omani citizens free of charge and the cost for any overseas testing is also financed by the government (Rajab et al 2013).

As many of the rare genetic disorders are not amenable to treatment, PND is usually offered for the purpose of consideration of pregnancy termination. Several studies have already identified that the decision to terminate a pregnancy for a fetal abnormality is known to be linked to the perceived severity of the condition diagnosed (AbdulAzeez et al 2019; Alsulaiman and Hewison 2006; Abramsky et al 2001; Drugan et al 1990) Furthermore, patient acceptance of termination of pregnancy (TOP) as an option is closely related to acceptance of PND (Alkuraya and Kilani 2001, Wertz 1992), as those that may consider TOP are more likely to undertake PND. Islamic jurists have established strict parameters to guide TOP decisions for fetal indications. In 1990, a Fatwa (an Islamic edict) was issued by the
Islamic Jurisprudence (Fiqh) Council of the World Islamic League that allowed for termination, for fetal indications, under strict requirements. These requirements included as follows: (1) that the condition is associated with a severe malformation leading to a shortened period of life (2); that the condition should not be amenable to treatment or management; and (3) the diagnosis should be confirmed by three experts. In addition, (4) the request for termination should be electively supported by both the parents. Importantly, (5) the PND and TOP should be performed before 120 days of conception (19-week gestation). This period correlates with the time of ensoulment according to the Hadith (sayings) of the Prophet Mohammed (Al-Matary and Ali 2014; El-Hashemite 1995; Sasongko et al 2010). Certain Islamic schools of thoughts (sects) interpret this time period as 40 days postconception and for these sects, TOP prior to ensoulment would not be feasible with the available invasive options for PND (Aramesh 2007). Islam is the state religion in Oman, with most of the population practicing Ibadi and Sunni and a minority of communities Shi'a.

In many Arab countries, including Oman, medical termination of pregnancy is still seen as culturally or traditionally unacceptable, with TOP being largely avoided in Muslim communities. In part, the reluctance to accept this as a preventative option may reflect the sect an individual or community follows (Bittles and Hamamy 2010) or unawareness of the Fatwa that governs TOP for fetal indications (Alkuraya and Kilani 2001). Studies on the acceptance of prenatal diagnostic procedures have been mostly conducted in the West and have shown a higher level of uptake than the limited studies performed in the Middle East (Alkuraya and Kilani 2001). A few studies have examined the attitudes toward pregnancy termination with fetal abnormalities within Islamic societies, namely from Saudi Arabia (AbdulAzeez et al 2019; Alkuraya and Kilani 2001; Alshalan and Alfadel 2019; Alsulaiman and Hewison 2006; Gaboon et al 2017). Although anticipated behavior is important when establishing preventative programs, it does not always reflect actual behavior. This study was therefore undertaken to be able to identify the actual uptake of PND for single gene disorders from this part of the world. The present study was carried out at the only two tertiary centers in Oman where PND was performed for single gene disorders from 2012 to 2020 . These centers are both located in Muscat, the capital city of Oman.

\section{Method}

A retrospective, descriptive study was conducted at SQUH and RH in Oman, during which the medical records of all women who performed CVS or amniocentesis, for a suspected single gene disorder, were reviewed. Invasive testing 
was offered to these women due to specific ultrasound findings (for example, features suggestive of thanatophoric dysplasia), known molecularly diagnosed case in a previous pregnancy or child or known family history with positive molecular confirmation where premarital genetic testing or carrier testing had confirmed carrier status in parents. Whole exome sequencing and chromosomal microarray, in the prenatal setting, are not offered in Oman and therefore no cases of this nature were included in the study. Information retrieved from medical records included as follows: year of procedure, tribe of the patient, prevalence of consanguinity and regional location, condition tested for including gene and variant details, type of invasive test performed (CVS or amniocentesis), result and outcome of pregnancy-related decisions (for TOP eligible cases). In the absence of detailed national guidelines in Oman governing TOP for fetal indications, internally developed guidelines at the Genetic and Development Medicine Clinic at SQUH were adopted as a standard operating procedure for this purpose (Table 1). The adopted guidelines abide to the Royal Decree governing the practice of the medical profession and allied health professions (Royal Decree 75/2019, 2019). Although other hospitals within Oman are able to offer invasive testing for chromosomal disorders, SQUH and RH are the only two available centers, within the country, where PND for a fetus with a suspected single gene disorder can be facilitated. The information reported in this study, therefore, reflects the trend for the entire country. Formal documentation of PND requests was recorded from 2012, following the inception of the genetic clinic at SQUH in 2011, and therefore depicts the year data collection was initiated from both of the centers. Ethical approval was obtained for the study by the Ethics Committee, College of Medicine and Health Sciences, Sultan Qaboos University (MREC \#2071) and the Scientific Research Committee, Royal Hospital (\#87/2019).

\section{Results}

A total of 148 invasive procedures were performed for PND of single gene disorders from January 2012 to December 2020 at the obstetric units at SQUH and RH for 114 families. More CVS procedures $(n=91 ; 61.5 \%)$ were performed than amniocenteses $(n=57 ; 38.5 \%)$ and a significant increase in the number of procedures can be seen per year with a sevenfold increase in the rate of procedures: from three in 2012 to 21 in 2020 (Fig. 1). For six procedures, testing was repeated due to analysis failure following the detection of significant maternal contamination (three were for CVS and three for amniocentesis). Table 2 describes the number of invasive procedures performed in successive pregnancies within the cohort. For 52 of the 114 women (45.6\%), PND was requested again in a future pregnancy. A total of 64 different diagnoses were tested for in at-risk pregnancies. The majority of conditions being tested for were inherited in an autosomal recessive manner $(61 / 64 ; 95.3 \%)$, two (2/64; $3.1 \%$ ) were associated with a dominant inheritance pattern, and one $(1 / 64 ; 1.6 \%)$ with X-linked inheritance. The most frequently requested test performed was for spinal muscular atrophy type 1 (SMA) $(17 / 64 ; 26.6 \%)$, followed by arthrogryposis, renal dysfunction, and cholestasis syndrome (5/64; $7.8 \%$ ). Table 3 provides further details of the conditions for

Table 1 Criteria to guide termination of pregnancy-related decisions for genetic disorders in Oman

\section{Guidelines defining eligibility for termination of pregnancy of genetic disorders*}

Criteria pertaining to the condition
1. The condition results in severe and debilitating congenital malfor-
mations or developmental outcomes or severe organ system dysfunc-
tion WITH NO presently available cure or therapy clinically proven
to significantly alter these outcomes 1
2. The condition is congenital or of infantile onset
3. The natural history of the condition is established. For ultra-rare
conditions with poorly established natural history, the condition
should have consistently followed the same clinical course among
affected relatives in the same families or in families known to the
genetic clinic
4. The condition does not show significant variability in severity of the
phenotype or in penetrance in a way that impedes reliable prediction
of the outcomes

Criteria pertaining to diagnostic confirmation

5 . The condition is genetically confirmed ${ }^{2}$ (molecular confirmation or chromosomal where appropriate)

6. Only pathogenic (P) or likely pathogenic (LP) variants (Harrison et al 2019; Richards et al 2015) should be entertained as causative when considering families for prenatal diagnosis

7. Variants reported in clinical laboratories to be of uncertain significance maybe entertained only if reclassified by a clinical laboratory to $\mathrm{P} / \mathrm{LP}$ based on further information supplied. For example, conclusive evidence from functional studies or clear biochemical perturbations or complete segregation of the variant with the phenotype

\footnotetext{
${ }^{1}$ Families with conditions that have ongoing phase III/IV therapeutic trials may only be considered for termination if they are of congenital, infantile, or of early childhood onset

${ }^{2}$ Certain conditions may be exempt from molecular confirmation. Examples would include conditions where the phenotype is well known to be lethal and obvious during prenatal diagnostic imagining such as anencephaly, pentalogy of Cantrell, and lethal skeletal dysplasias like achondrogenesis
}

* Both condition and diagnostic criteria should be met before termination of pregnancy can be offered as an option 
Fig. 1 Number of prenatal genetic diagnostic tests performed for single gene disorders between 2012 and 2020 $(n=148)$. Data includes repeat tests performed due to analysis failure. Repeat testing included one case in 2013, 2016, 2017, and 2020 and two cases in 2018

\section{Invasive procedures for single gene disorders between 2012-2020}

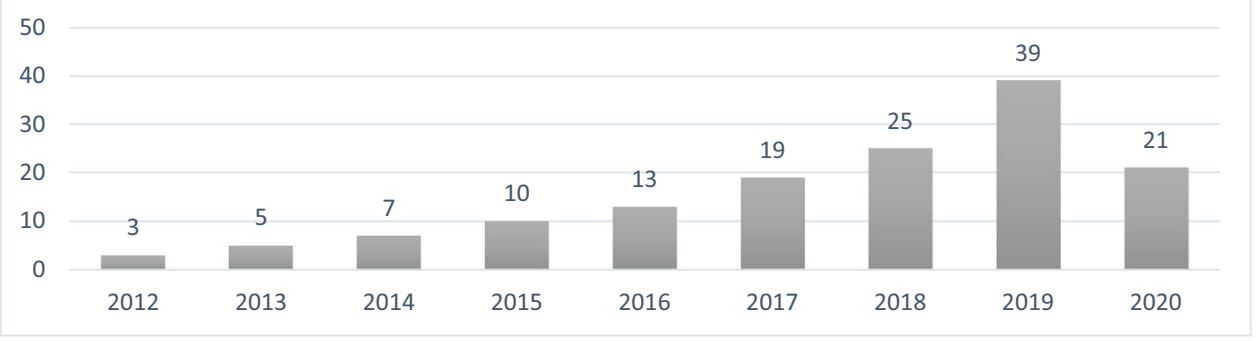

Table 2 Number of invasive procedures performed in successive pregnancies within the cohort

\begin{tabular}{lll}
\hline Number of PND's undertaken & $\begin{array}{l}\text { Number per } \\
\text { category }\end{array}$ & Percentage \\
\hline Single request for PND & 90 & $60.80 \%$ \\
Repeated PND twice & 42 & $28.40 \%$ \\
Repeated PND three times & 6 & $4.05 \%$ \\
Repeated PND four times & 4 & $2.70 \%$ \\
Repeated PND due to analysis failure & 6 & $4.05 \%$ \\
Total & 148 & $100 \%$ \\
\hline
\end{tabular}

$P N D$, prenatal genetic diagnosis

which PND was performed. The variant details have purposefully been omitted to maintain the privacy of these families. It is not unusual to be able to identify the tribal origin or geographic location of individuals in Oman if the variant details are known for a particular rare condition (Rajab et al 2015). Considering all results where a genetic diagnosis was achieved, 39/142 (27.5\%) identified an affected pregnancy and 103/142 (72.5\%) an unaffected pregnancy. Of the 39 cases where an affected pregnancy was identified, 28 couples terminated the affected pregnancy $(71.8 \%)$. For the remaining 11 cases $(28.2 \%)$ where an affected pregnancy was identified, the information was utilized for management related decisions (planning delivery mode, delivery hospital, future organ transplant planning) for five (45.4\%) families and for parental anxiety for seven families (63.6\%). Two families opted for TOP abroad for conditions that were not deemed eligible in Oman. Information on individual TOP outcomes (within each disease category) are not included to maintain the privacy of the families' decisions. Only one report of pregnancy loss was documented following PND, corresponding to a procedure-related loss rate of $0.7 \%(1 / 148)$.

Figure 2 illustrates the distribution of couples according to their residence in Oman for the PND's that were performed. The population size per governorate, as recorded by the 2010 Oman Census data, is also provided on the map (Governorates of Oman 2021). The majority of requests were from the Albatinah (40/148; 27\%), Muscat (40/148; $27 \%)$, and Alsharqiya $(30 / 148 ; 20.3 \%)$ governorates. Consanguinity was documented for all couples as part of the prenatal genetic counseling session when detailed family pedigrees were recorded. When considering parental relations, 63\% (72/114) of couples were consanguineous parents related as second cousins or closer. First cousin marriages were reported in 61 families $(53.5 \%)$, second cousins in seven $(6.1 \%)$, double first cousins in two families $(1.7 \%)$, and first cousins once removed in two families (1.7\%). The average coefficient of inbreeding $(F)$ was 0.061 . The remainder of couples were endogamous $(7 / 114 ; 6.2 \%)$ and 35 were unrelated (30.7\%).

\section{Discussion}

The majority of studies undertaken on PND and TOP have been conducted in Western populations and where reported for the Middle East, have largely focused on the attitudes toward PND and TOP in Saudi-Arabia (AbdulAzeez et al 2019; Alkuraya and Kilani 2001; Alshalan and Alfadel 2019; Alsulaiman and Hewison 2006; Gaboon et al 2017). Although anticipated behavior is useful when determining the need for establishing services, the hypothetical nature is not necessarily predictive of actual behavior. Our study is the first to report on this topic in the Sultanate of Oman. We identified that 114 Omani families utilized PND services for early detection of single gene disorders in an at-risk pregnancy over the 9-year study period with a steady rise in requests for PND from 2012 to 2019. The dip in requests for 2020 can be explained by the impact of COVID-19 on the healthcare system in 2020 including prioritizing COVID-19 patients as well as patient avoidance of hospitals. The border closures in Oman during this year, between governorates, also meant that families interested in PND who lived outside of the Muscat governorate were unable to access services (as both tertiary centers are located within this governorate). Differences in the regional distribution of families undertaking PND (Fig. 2) could also be partly explained by proximity 
Table 3 Genetic disease in cohort of patients undertaking prenatal genetic diagnosis (PND)

\begin{tabular}{|c|c|c|c|c|}
\hline & Gene & Condition (OMIM) & Inheritance & $\begin{array}{l}\text { Number of tests } \\
\text { performed for each } \\
\text { condition }^{\text {a }}\end{array}$ \\
\hline 1 & AARS2 & Combined oxidative phosphorylation deficiency 8 & $\mathrm{AR}$ & 1 \\
\hline 2 & AGXT & Primary hyperoxaluria & $\mathrm{AR}$ & 2 \\
\hline 3 & ALDH3A2 & Sjogren-Larsson syndrome & $\mathrm{AR}$ & 1 \\
\hline 4 & ALG12 & Congenital disorder of glycosylation, type Ig & $\mathrm{AR}$ & 1 \\
\hline 5 & AMPD2 & Pontocerebellar hypoplasia, type 9 & $\mathrm{AR}$ & 1 \\
\hline 6 & ANTXR2 & Hyaline fibromatosis syndrome & $\mathrm{AR}$ & 2 \\
\hline 7 & AP3B2 & Developmental and epileptic encephalopathy 48 & $\mathrm{AR}$ & 1 \\
\hline 8 & AP3D1 & Hermansky-Pudlak syndrome 10 & $\mathrm{AR}$ & 1 \\
\hline 9 & ARSA & Metachromatic leukodystrophy & AR & 3 \\
\hline 10 & ASL & Argininosuccinic aciduria & AR & 1 \\
\hline 11 & ASPA & Canavan disease & $\mathrm{AR}$ & 1 \\
\hline 12 & ATP8A2 & Cerebellar ataxia, mental retardation, and dysequilibrium syndrome 4 & AR & 1 \\
\hline 13 & B3GALNT2 & $\begin{array}{l}\text { Muscular dystrophy-dystroglycanopathy (congenital with brain and eye anomalies, type } \\
\text { A, 11) }\end{array}$ & $\mathrm{AR}$ & 1 \\
\hline 14 & CPS1 & Carbamoylphosphate synthetase I deficiency & $\mathrm{AR}$ & 2 \\
\hline 15 & CTSA & Galactosialidosis & $\mathrm{AR}$ & 3 \\
\hline 16 & DGUOK & Mitochondrial DNA depletion syndrome 3 (hepatocerebral type) & $\mathrm{AR}$ & 2 \\
\hline 17 & DLAT & Pyruvate dehydrogenase E2 deficiency & $\mathrm{AR}$ & 1 \\
\hline 18 & DMD & Duchenne muscular dystrophy & XL & 1 \\
\hline 19 & EIF2AK3 & Wolcott-Rallison syndrome & $\mathrm{AR}$ & 1 \\
\hline 20 & EMC1 & Cerebellar atrophy, visual impairment, and psychomotor retardation & $\mathrm{AR}$ & 1 \\
\hline 21 & ERCC5 & Xeroderma pigmentosum, group G/Cockayne syndrome & $\mathrm{AR}$ & 2 \\
\hline 22 & ETFDH & Glutaric acidemia II & $\mathrm{AR}$ & 3 \\
\hline 23 & FBXL4 & Mitochondrial DNA depletion syndrome 13 (encephalomyopathic type) & $\mathrm{AR}$ & 2 \\
\hline 24 & FGFR3 & Thanatophoric dysplasia, type II & $\mathrm{AD}$ & 2 \\
\hline 25 & FKTN & $\begin{array}{l}\text { Muscular dystrophy-dystroglycanopathy (congenital without mental retardation) type } \\
\text { 4B }\end{array}$ & $\mathrm{AR}$ & 1 \\
\hline 26 & FRAS1 & Fraser syndrome & AR & 1 \\
\hline 27 & GALC & Krabbe disease & $\mathrm{AR}$ & 1 \\
\hline 28 & GAN & Giant axonal neuropathy & AR & 1 \\
\hline 29 & GLB1 & GM1-gangliosidosis, type I & $\mathrm{AR}$ & 1 \\
\hline 30 & HBB & Beta thalassemia & AR & 2 \\
\hline 31 & HSD17B4 & Perrault syndrome 1 & $\mathrm{AR}$ & 1 \\
\hline 32 & IBA57 & Multiple mitochondrial dysfunctions syndrome 3 & $\mathrm{AR}$ & 1 \\
\hline 33 & IDUA & Mucopolysaccharidosis type I (Hurler) & $\mathrm{AR}$ & 1 \\
\hline 34 & IFT172 & Short-rib thoracic dysplasia 10 with or without polydactyly & $\mathrm{AR}$ & 1 \\
\hline 35 & ITGA8 & Renal hypoplasia/aplasia 1 & AR & 1 \\
\hline 36 & LAMA3 & Epidermolysis bullosa, junctional, Herlitz type & AR & 1 \\
\hline 37 & MPV17 & Mitochondrial DNA depletion syndrome type 6 & AR & 1 \\
\hline 38 & NAGLU & Mucopolysaccharidosis type IIIB (Sanfilippo B) & AR & 1 \\
\hline 39 & NFASC & Neurodevelopmental disorder with central and peripheral motor dysfunction & $\mathrm{AR}$ & 1 \\
\hline 40 & OSTM1 & Osteopetrosis & $\mathrm{AR}$ & 2 \\
\hline 41 & $\mathrm{PC}$ & Pyruvate carboxylase deficiency & AR & 1 \\
\hline 42 & PCCB & Propionic acidemia & $\mathrm{AR}$ & 1 \\
\hline 43 & PEX1 & Peroxisome biogenesis disorder 1A (Zellweger) & $\mathrm{AR}$ & 7 \\
\hline 44 & PEX14 & Peroxisome biogenesis disorder 13A (Zellweger) & $\mathrm{AR}$ & 1 \\
\hline 45 & PEX26 & Peroxisome biogenesis disorder 7A (Zellweger) & $\mathrm{AR}$ & 2 \\
\hline 46 & PGAP3 & Hyperphosphatasia with mental retardation syndrome 4 & AR & 1 \\
\hline
\end{tabular}


Table 3 (continued)

\begin{tabular}{|c|c|c|c|c|}
\hline & Gene & Condition (OMIM) & Inheritance & $\begin{array}{l}\text { Number of tests } \\
\text { performed for each } \\
\text { condition }^{\text {a }}\end{array}$ \\
\hline 47 & PKHD1 & Polycystic kidney disease 4 , with or without hepatic disease & $\mathrm{AR}$ & 1 \\
\hline 48 & PLA2G6 & Neurodegeneration with brain iron accumulation $2 \mathrm{~B}$ & AR & 1 \\
\hline 49 & PRUNE1 & Prune-1 syndrome & AR & 3 \\
\hline 50 & RAB3GAP1 & Warburg-Micro syndrome & AR & 2 \\
\hline 51 & RARS & Hypomyelinating leukodystrophy type 9 & $\mathrm{AR}$ & 1 \\
\hline 52 & RARS2 & Pontocerebellar hypoplasia, type 6 & AR & 1 \\
\hline 53 & RECQL4 & RAPADILINO syndrome & AR & 1 \\
\hline 54 & SMN1 & Spinal muscular atrophy-1 & $\mathrm{AR}$ & 17 \\
\hline 55 & SPINK5 & Netherton syndrome & $\mathrm{AR}$ & 1 \\
\hline 56 & STT3A & Congenital disorder of glycosylation, type Iw & $\mathrm{AR}$ & 2 \\
\hline 57 & SUOX & Sulfite oxidase deficiency & AR & 3 \\
\hline 58 & TBCE & Hypoparathyroidism-retardation-dysmorphism syndrome & AR & 3 \\
\hline 59 & TINF2 & Dyskeratosis congenita & $\mathrm{AD}$ & 1 \\
\hline 60 & TMEM138 & Joubert syndrome 16 & $\mathrm{AR}$ & 1 \\
\hline 61 & TRIP11 & Achondrogenesis, type IA & $\mathrm{AR}$ & 1 \\
\hline 62 & TRNT1 & $\begin{array}{l}\text { Sideroblastic anemia with B-cell immunodeficiency, periodic fevers, and developmen- } \\
\text { tal delay }\end{array}$ & AR & 1 \\
\hline 63 & UGT1A1 & Crigler-Najjar syndrome, type I & AR & 1 \\
\hline 64 & VPS33B & Arthrogryposis, renal dysfunction, and cholestasis 1 & AR & 5 \\
\hline
\end{tabular}

a'Data includes repeat procedures. Individual TOP outcomes were not recorded to maintain the privacy of the families' decisions. $A R$, autosomal recessive; $A D$, autosomal dominant; $X L, \mathrm{X}$-linked

to Muscat, where greater numbers reflect closer proximity to PND services as well as a higher number of requests from more densely populated governorates. The representation from Dhofar region, albeit geographically distant from Muscat, can be explained by the existing collaboration between SQUH and RH and the tertiary hospital in the region and well-established transport routes between the governorates.

Despite CVS being associated with a slightly higher risk of miscarriage and a lower diagnostic accuracy, CVS was preferred to amniocentesis (61.5\% versus 38.5\%) among the cohort of this study. Although the reasons for this could not be identified from the data, based on our experience with Omani families, a number of explanations could account for this. Primarily, testing in first trimester as opposed to the second trimester carries a benefit in terms of anxiety as well as access to earlier termination. Furthermore, for couples who intend to terminate an affected pregnancy and where close family are not in support of termination, non-disclosure of pregnancy status would be easier in the first trimester when the pregnancy would be less physically apparent. Lastly, as the cut-off period for termination due to fetal indications is 19 weeks, results from repeat testing following amniocentesis may be more likely to fall beyond this period, rendering families without this preventative option. An analysis failure rate of $4 \%(6 / 148)$ was identified in our cohort. This rate is slightly lower than the $6 \%$ usually reported for second sampling or repeat procedures (Navaratnam and Alfirevic 2021). Repeat procedures yielded an answer for all cases within the 19-week period, except for one amniocentesis case, where an unaffected fetus was luckily identified at 20 -week gestation. Considering the small sample size when calculating our cohort's miscarriage risk, it would be difficult to compare the procedure-related loss rate of our study to other larger studies; however, our number $(1 / 148 ; 0.7 \%)$ was not significantly higher than figures quoted in the literature (Akolekar et al 2015, Practice Bulletin No. 162 2016).

As Table 3 illustrates, a large percentage of PND requests in Oman were for autosomal recessive genetic disorders. This is not unexpected as Rajab et al (2005), based on a large population-based study involving 420000 live births from 1993 to 2002, identified autosomal recessive disorders to be the commonest of the genetic disorders within Oman. This increased propensity of some of the recessive disorders has previously been attributed to the practice of consanguinity and endogamous marriages within some of the populations of the Arab communities (Rajab et al 2015). The consanguinity rate of $63 \%(72 / 114)$ in our study is higher than that of the general population (52\%) suggesting that consanguinity could be contributing to the increased tendency of occurrence of these otherwise rare autosomal recessive disorders within these families. More commonly occurring 
Fig. 2 Geographic distribution of couples requesting prenatal genetic diagnosis (PND) in Oman. $n=$ PND requests per governorates. P, population size as per 2010 Oman Census data (Governorates of Oman 2021). * Sultan Qaboos University Hospital and Royal Hospital are both located within the capital city of Muscat (Muscat governorate). Albatinah and Alsharqiya are made up of a North and South governorate. PND data for the entire region (North and South) are shown for these two governorates

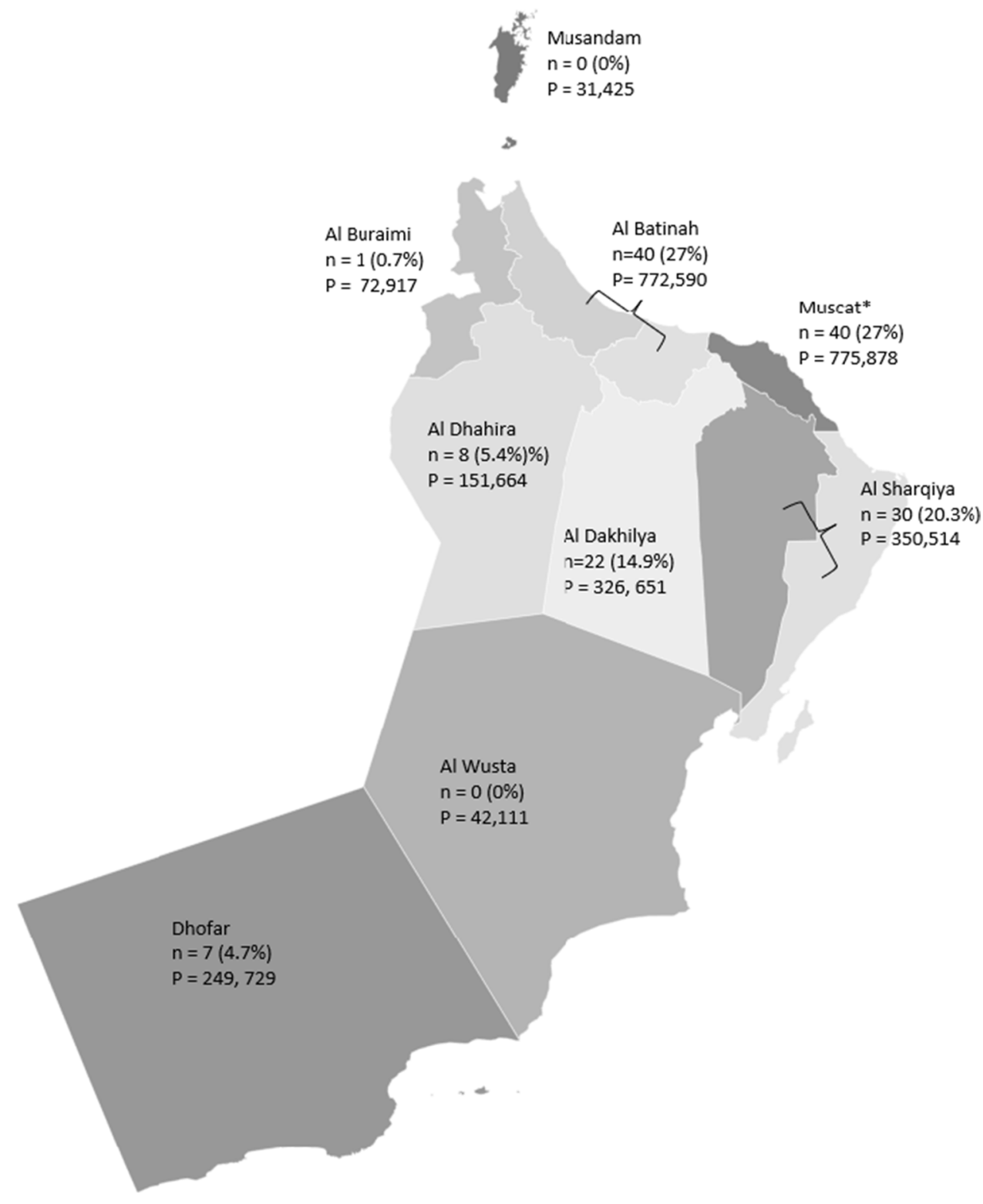

recessive disorders, such as SMA and thalassemia, are also listed among the rare recessive disorders for which PND was performed. Although SMA was the most frequently requested PND test, contributing to over 10\% (17/148) of PND's performed, this number is probably an under-representation. For several years, disease-modifying interventions like antisense oligonucleotide therapy became available to families in Oman, with the result that the condition was no longer eligible for termination (and therefore families at-risk of this order may not have considered PND if TOP was not an available option to them). Conditions for which therapeutic options exist that alter the course of the condition are not deemed eligible for termination based on the Fatwa. Thus, haemoglobinopathies, which are known to occur at an incidence of 3.5-4.7/1000 in Oman, one of the highest in the world and the fact that $2-3 \%$ of the population are carriers for beta-thalassemia (Al-Riyami and Ebrahim 2003; Rajab et al 2000), also did not contribute significantly to the number of PND requests in the study cohort. Although the Fatwa outlines the conditions that need to be met to be able to offer TOP for fetal indications (addressed in detail earlier), there is no consensus on which fetal anomalies are acceptable indications for TOP. Furthermore, significant differences exist between regional Muslim countries, with regard to the definition of serious medical conditions for which TOP may be considered. To overcome this, organizationspecific guidelines, used as standard operating procedures by SQUH and RH, have been used to define objective criteria to guide this process. Table 1 provides an overview of criteria that have been considered when making these decisions in 
Oman, namely, the condition (classification of severity, age of onset, natural history, and variability in expression and penetrance) and diagnostic confirmation.

Alkuraya and Kilani (2001) and Wertz (1992) have previously shown that the attitude toward termination and request for PND are closely related. Our study provides further support for this among the Omani population as $71.8 \%$ of couples terminated the affected pregnancy. As the Fatwa can be used by any Muslim anywhere in the world (Jafri et al 2012), it is important for healthcare professionals to be familiar with the content to enable proper education and counseling of families in accordance with Islam. Based on our personal experience with hundreds of Omani families, patients representing all sects present in the Omani population have requested PND to aid decisions regarding TOP. This suggests that a family's sect should not be taken as a proxy for their attitudes toward, either for or against, termination of pregnancy. Thus, decisions related to acceptability among individuals from a specific sect should be taken on an individual basis.

The findings of this study provide evidence that PND with the option of TOP for an affected pregnancy is a publicly accepted intervention in Oman. The escalation in the number of requests for PND over the study period together with the fact that $45.6 \%$ of couples (52/114) elected to repeat PND in successive pregnancies serves to argue that Omani Muslim couples consider PND a reproductive option to prevent the occurrence of a severe genetic disorder.

Acknowledgements We would like to acknowledge Yusra Al Balushi, Amel Al Foori, and Saida Al Hinai for their efforts related to gathering data for the study.

Author contribution All authors contributed to the study design, conception, and material preparation. Data collection and analysis were performed by Zandré Bruwer, Khalsa Al Kharusi, and Salwa Al Ubaidani. The first draft of the manuscript was written by Zandré Bruwer and all authors read and approved the final manuscript.

\section{Declarations}

The study was conducted retrospectively from data obtained for clinical purposes. Ethical approval was obtained for the study by the Ethics Committee, College of Medicine and Health Sciences, Sultan Qaboos University, and the Scientific Research Committee, Royal Hospital.

Conflict of interest The authors declare no competing interests.

\section{References}

AbdulAzeez S, Al Qahtani N, Almandil N, Al-Amodi A, Aldakeel S, Ghanem N, Alkuroud D, AlTurki A, AlQattan Q, Alghamdi A, Alhur N, Al Taifi H, Aljofi H, Jermy B, Raman V, Giambona A, Maggio A, Borgio JF (2019) Genetic disorder prenatal diagnosis and pregnancy termination practices among high consanguinity population. Saudi Arabia Sci Rep 9(1):17248. https://doi.org/10. 1038/s41598-019-53655-8
Abramsky L, Hall S, Levitan J, Marteau TM (2001) What parents are told after prenatal diagnosis of a sex chromosome abnormality: interview and questionnaire study. BMJ 322(7284):463-466. https://doi.org/10.1136/bmj.322.7284.463

Akolekar R, Beta J, Picciarelli G, Ogilvie C, D’Antonio F (2015) Procedure-related risk of miscarriage following amniocentesis and chorionic villus sampling: a systematic review and metaanalysis. Ultrasound Obstet Gynecol 45(1):16-26. https://doi. org/10.1002/uog.14636

Al-Gazali L, Hamamy H, Al-Arrayad S (2006) Genetic disorders in the Arab world. BMJ 333(7573):831-4. https://doi.org/10.1136/ bmj.38982.704931.AE

Alkuraya FS, Kilani RA (2001) Attitude of Saudi families affected with hemoglobinopathies towards prenatal screening and abortion and the influence of religious ruling (Fatwa). Prenat Diagn 21(6):448-451. https://doi.org/10.1002/pd.76

Al-Matary A, Ali J (2014) Controversies and considerations regarding the termination of pregnancy for foetal anomalies in Islam. BMC Med Ethics 15:10. https://doi.org/10.1186/ 1472-6939-15-10

Al-Riyami A, Ebrahim G. (2003) Genetic blood disorders survey in the Sultanate of Oman. J Trop Pediatr;49 Suppl 1:i1-20.

Al-Riyami A, Afifi M, Al-Kharusi H, Morsi M. (2000) National Health Survey 2000, vol 2. Reproductive Health Survey. Ministry of Health, Muscat, 2000.

Alshalan M and Alfadel M. (2019) Attitudes to prenatal diagnosis and termination of pregnancy for fetal abnormalities in Saudi couples: a single center experience. Journal of Biochemical and Clinical Genetics ;2(2):99-106. https://doi.org/10.24911/JBCGenetics/ $183-1574152719$

Alsulaiman A, Hewison J (2006) Attitudes to prenatal and preimplantation diagnosis in Saudi parents at genetic risk. Prenat Diagn 26(11):1010-1014. https://doi.org/10.1002/pd.1544

Al-Thihli K, Al-Murshedi F, Al-Hashmi N, Al-Mamari W, Islam MM, Al-Yahyaee SA (2014) Consanguinity, endogamy and inborn errors of metabolism in Oman: a cross-sectional study. Hum Hered 77(1-4):183-188. https://doi.org/10.1159/000362686

Aramesh K (2007) The influences of bioethics and Islamic jurisprudence on policy-making in Iran. Am J Bioeth 7(10):42-44. https:// doi.org/10.1080/15265160701588196

Bittles A (2001) Consanguinity and its relevance to clinical genetics. Clin Genet 60(2):89-98. https://doi.org/10.1034/j.1399-0004. 2001.600201.x

Bittles A, Hamamy H (2010) Endogamy and consanguineous marriage in Arab populations. In: Teebi AS (ed) Genetic disorders among Arab populations, 2nd edn. Springer, Heidelberg Dordrecht London, New York, pp 85-10

Bruwer Z, Achandira U, Al Kharousi K, Al-Kindy A (2014) Existing challenges associated with offering prenatal genetic diagnosis in an Arab society in the Sultanate of Oman. Genet Couns 23(6):928-32. https://doi.org/10.1007/s10897-014-9764-x

Drugan A, Greb A, Johnson MP, Krivchenia EL, Uhlmann WR, Moghissi KS, Evans MI (1990) Determinants of parental decisions to abort for chromosome abnormalities. Prenat Diagn 10(8):483-490. https://doi.org/10.1002/pd.1970100802

El-Hashemite N (1995) Genetic malformation in children, its causes, and the Islamic view in preventive procedures (in Arabic Language). Dar Al-Hekma, London

Gaboon NEA, Bakur KH, Edrees AY, Al-Aama JY. (2017) Erratum: Attitude toward prenatal testing and termination of pregnancy among health professionals and medical students in Saudi Arabia. J Pediatr Genet. Sep;6(3):e1. doi: https://doi.org/10.1055/s0037-1603198. Epub 2017 May 10. Erratum for: J Pediatr Genet. 2017;6(3):149-154.

Governorates of Oman. (2021) Wikipedia. Retrieved September 21 2021 from https://en.wikipedia.org/wiki/Governorates_of_Oman. 
Harrison S, Biesecker L, Rehm H (2019) Overview of specifications to the ACMG/AMP variant interpretation guidelines. Curr Protoc Hum Genet 103:e93. https://doi.org/10.1002/cphg.93

Jafri H, Ahmed S, Ahmed M, Hewison J, Raashid Y, Sheridan E (2012) Islam and termination of pregnancy for genetic conditions in Pakistan: implications for Pakistani health care providers. Prenat Diagn 32(12):1218-1220. https://doi.org/10.1002/pd.3987

Modell B. (2002) Possibilities for the control of congenital and genetic disorders in Oman. Sultanate of Oman: Report of WHO Consultant to Ministry of Health.

Navaratnam K, Alfirevic Z; Royal College of Obstetricians and Gynaecologists. (2021) Amniocentesis and chorionic villus sampling: Green-top Guideline No. 8. BJOG. https://doi.org/10.1111/14710528.16821.

Practice Bulletin No (2016) 162 (2016) Prenatal diagnostic testing for genetic disorders. Obstet Gynecol 127(5):e108-e122. https://doi. org/10.1097/AOG.0000000000001405

Rajab A, Patton MA (2000) (2000) A study of consanguinity in the Sultanate of Oman. Ann Hum Biol 27(3):321-326. https://doi. org/10.1080/030144600282208

Rajab AG, Patton MA, Modell B (2000) Study of hemoglobinopathies in Oman through a national register. Saudi Med J 21(12):1168-1172

Rajab A, Bappal B, Al-Shaikh H, Al-Khusaibi S, Mohammed A (2005) Common autosomal recessive diseases in Oman derived from a hospital-based registry. J Community Genet 8(1):27-30. https:// doi.org/10.1159/000083334

Rajab A, Al Rashdi I, Al Salmi Q (2013) Genetic services and testing in the Sultanate of Oman Sultanate of Oman steps into modern genetics. J Community Genet 4(3):391-7. https://doi.org/10.1007/ s12687-013-0153-1

Rajab A, Al Salmi Q, Jaffer J, Mohammed AJ, Patton M (2014) Congenital and genetic disorders in the Sultanate of Oman First attempt to assess healthcare needs. J Community Genet 5(3):2839. https://doi.org/10.1007/s12687-014-0182-4
Rajab A, Hamza N, Al Harasi S, Al Lawati F, Gibbons U, Al Alawi I, Kobus K, Hassan S, Mahir G, Al Salmi Q, Mons B, Robinson P. (2015) Repository of mutations from Oman: the entry point to a national mutation database. F1000Res 23;4:891. https://doi.org/ 10.12688/f1000research.6938.1.

Richards S, Aziz N, Bale S, Bick D, Das S, Gastier-Foster J, Grody WW, Hegde M, Lyon E, Spector E, Voelkerding K, Rehm HL; ACMG Laboratory Quality Assurance Committee. (2015) Standards and guidelines for the interpretation of sequence variants: a joint consensus recommendation of the American College of Medical Genetics and Genomics and the Association for Molecular Pathology. Genet Med 17(5):405-424. https://doi.org/10.1038/ $\operatorname{gim} .2015 .30$

Royal Decree 75/2019. (2019) Promulgating the law governing the practice of the medical profession and allied health professions. Official Gazette No 1317. 6 November. Retrieved 13 January 2022 from https://mjla.gov.om/legislation/decrees/details.aspx? $\mathrm{Id}=1131 \&$ type $=$ L\&lang $=\mathrm{a}$

Sasongko TH, Salmi AR, Zilfalil BA, Albar MA, Mohd Hussin ZA (2010) Permissibility of prenatal diagnosis and abortion for fetuses with severe genetic disorder: type 1 spinal muscular atrophy. Ann Saudi Med 30(6):427-431. https://doi.org/10.4103/ 0256-4947.72259

Wertz DC, Janes SR, Rosenfield JM, Erbe RW (1992) Attitudes toward the prenatal diagnosis of cystic fibrosis: factors in decision making among affected families. Am J Hum Genet 50(5):1077-1085

Publisher's note Springer Nature remains neutral with regard to jurisdictional claims in published maps and institutional affiliations. 